\title{
Teaching reform of Engineering Graphics - on the relationship between hand drawing and computer drawing
}

\author{
Huanyun Wang ${ }^{1}$ Chunhui Pan ${ }^{2}$ \\ ${ }^{1}$ Department of Mechanical Engineering, Cangzhou Normal University, Cangzhou \\ 061001, Hebei, China \\ ${ }^{2}$ Department of Chemistry, Cangzhou Normal University, Cangzhou 061001, Hebei, \\ China
}

\begin{abstract}
Engineering graphics is an important basic course in technology and engineering college. With the development of computer technology, various drawing software emerge.The integration of the traditional engineering graphics theory and advanced computer technology will become the development trend of engineering graphics. In this paper, the author analyzes the relation of hand drawing and computer graphics through years of teaching experience, build a new teaching system, and put forward the idea that the two should be combined and expanded into other areas so that we can achieve the aim of teaching of Engineering Graphics.
\end{abstract}

Keywords: Engineering graphics ; Manual drawing; Computer graphics; teaching reform

\section{Introduction}

Engineering graphics is an important basic course at Institutions of higher learning. Currently in engineering practice manual drawing has many disadvantages such as time-consuming, low efficiency and high labor intensity and drawing precision is not easy to guarantee while the advantages of computer graphics is obvious such as fast speed, high efficiency and good accuracy. Therefore, it has been widely used and many people propose to throw away the drawing board in the teaching of Engineering Graphics. How to integrate the two has become an urgent problem to be solved for colleges and universities.

\section{The relationship between the two 2.1. Hand drawing is the foundation}

Traditional manual drawing training is down-to-earth, step by step and plays an irreplaceable role in developing the students' ability of space conception and Graphic expression ability. If there is no manual drawing training, there is no ability to plot and interpret the drawings and it is difficult to use the computer to draw, identify, and correct the engineering drawings. Therefore so we think that " throwing away the drawing board " can only be technical, rather than in the teaching. Even if we can use computer all the time, it is necessary to have essential manual training. Practice has proved that the manual drawing can make students pay attention to the digestion and application of concept and theory, improve their ability to analyze and solve problems and is the cultivation of graphics thinking. Computer drawing is only the tool and method innovation. 
The thinking in images of engineers is not generated by computer graphics which emphasizes the skilled operation method and application of skills but rare space concept applications.

\section{2. computer graphics is a means}

Computer graphics data input has many advantages such as simple, easy to use, fast speed, less memory space, strong controllability and expressive force, and is conducive to teachers to operate actively according to the teaching requirements. AutoCAD, UG, Solid Works, CAD, CAXA electronic drawing board are Common software.

The biggest advantage of computer graphics is to exhibit complex parts with animation and three-dimensional graph. For example, when explaining expression method, we can use sectional-tangental drawing in AutoCAD to make presentation shown in fig. 1:

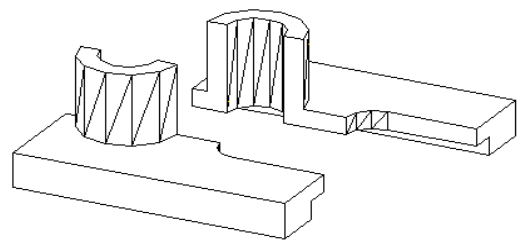

Fig. 1 Use the Slice command to split the $3 \mathrm{D}$ entity

In Fig. 1 we can see the cutting position, the section plane and the take-away part visually. And in this way when we draw the two-dimensional graphics the label of the section plane, profile line position and drawing are all very clear ${ }^{[1]}$.

\subsection{Integrate the two organically}

Engineering graphics knowledge lays the necessary foundation of computer graphics and facilitates students to understand and master in learning drawing software while the introduction of computer graphics solves a lot of tedious work in engineering graphics such as standard parts, the title bar and map calls, so the two are complementary to each other. Especially in engineering drawing sketch training, not only can save a lot of instrument drawing time to improve the learning efficiency but also meet the needs of computer graphics development. ${ }^{[2]}$ In order to integrate the two organically, we can optimize the teaching content and set up the corresponding engineering practice course to give students a component to let the students strengthen the concept of the axonometric drawing. Then use the engineering graphics knowledge to draw sketch manually according to the corresponding national standards and reduce the workload of instrument drawing. Finally we can use the advantages of computer graphics such as easy to edit and modify to make necessary modifications and annotation to improve drawing efficiency and precision

\section{3. construct new teaching content and teaching system}

\section{1. change the teaching content}

\subsubsection{Add and delete the contents of Engineering Graphics properly}

Those basic drawing functions provided in computer drawing need not explain carefully in engineering graphics such as the basic mapping of polygon, ellipse, and tangent ${ }^{[3]}$. Currently the engineering graphics III has a total of 64 hours, in which manual drawing accounts for 14 hours. Engineering graphics I is a total of 80 hours, in which manual drawing accounts for 16 hours, about $1 / 5$. The proportion is too big. Students spend a lot of time on how to use various instruments to draw graphics accurately. However, no matter how careful they are, they can not do so accurate like a computer. So hours of manual drawing class should be cut by $1 / 2$ and hours of computer graphics 
should be increased to change the manual maps to electronic maps.

\subsubsection{Offer practice course, strengthen the ability of spatial configuration and sketch training}

Make students to draw simple axonometric drawings by hand to learn the basic body to Strengthen their ability of space imagination and composition. Then offer engineering practice course to survey and map parts and components by sketch training to strengthen the teaching content and save equipment drawing time. Finally use the drawing software to position precisely in the computer and complete the graph.

\subsubsection{Expand into the field of industrial design}

Fuse the industrial design knowledge into teaching and permeate aesthetics and expressive connotation in the graphics, starting from the three-dimensional concept, 3D spatial analysis and 3D expression training to improve the space imagination of students and design the best product structure and morphology ${ }^{[4]}$. At the same time we can offer corresponding courses on 3D modeling, Virtual assembly and parallel design such as Solid Works, CAXA electronic drawing board to strengthen the students' practical ability of graphics so that we can enhance students' interest in learning and improve the teaching quality of graphics.

\subsection{The change of teaching methods}

\subsubsection{Change "indoctrination" into "guidance"}

Engineering graphics is a very practical course and it is necessary to do a certain amount of homework and practice to achieve the teaching requirements. Especially in "configuration training" and "two for three" teachers should guide the students, give full play to their initiation and strengthen their ability of space imagination. For example,

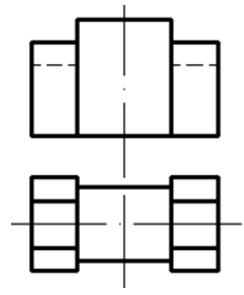

Fig. 2 Combination "two for three "
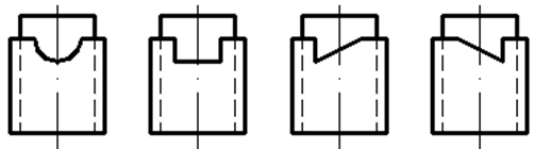

Fig. 3 Four kinds of answers

In Fig. 2 the front view and the vertical view are known and ask for the left view. Four kinds of answers in Fig. 3 are correct. We can not only motivate the learning interest of the students but also improve the quality of teaching.

\subsubsection{Build network teaching system}

CAI courseware can make full use of the advantage of computers to replace the traditional teaching using a limited number of blackboards, wall maps and models. CAI courseware can increase the amount of teaching information, and there are a large mount of entities, graphic symbols 3D animation which can improve the learning interest of the students greatly. The traditional teaching effect depends largely on the teacher's teaching level while the CAI courseware centralizes the teaching essence of many excellent teachers. Even if the teacher lectures for the first time, he can improve his teaching quickly with the help of CAI courseware. And the implementation of the network teaching can realize the interaction between teachers and students and make up for deficiencies in classroom teaching. 


\subsubsection{To create a rich and colorful graphics environment}

Because the course is arranged for the first grade students in the University, the students are not clear about the space concept of stereo and parts and especially poorly understand the process, structure and application of parts in mechanical drawing. Their perceptual knowledge is very little and they think this course is very difficult to learn. If we open a corresponding learning space in classrooms and have excellent work exhibition as well as arrange rich color models, it will stimulate students' interest in learning. In terms of computers, we can open computer rooms equipped with a variety of computer graphics software to increase the choices of students and improve the teaching quality.

\section{Conclusion}

Engineering drawing is a compulsory basic course in higher education. Whether in terms of improving the quality of students or the training of engineering practice ability, hand drawing and computer graphics are indispensable. Only to make full use of the foundamentality of manual drawing and the advancement of computer graphics, combine the two and construct new teaching content and teaching system can we truly achieve the teaching goal and improve the teaching quality.

\section{References}

[1] Shunxin Zhang, computer aided design and drafting. Beijing: Mechanical Industry Press, 2002.

[2] Caiyun Yuan. Engineering drawing. Beijing: Mechanical Industry Press, 2002.

[3] Mingchen Meng et al.. The Discussion on the Reformation of Engineering Grphics Education. Research in Teaching. 2005, 28(3): 225-228.

[4] Minglang Yu. Reflection and Exploration to the Teaching Reform of Engineering Drawing. Journal of Graphics. 2009,5:157-162. 